\title{
Controlled and sustained drug release performance of calcium sulfate cement porous $\mathrm{TiO}_{2}$ microsphere composites
}

This article was published in the following Dove Press journal: International Journal of Nanomedicine

\section{Wei Luo \\ Zhen Geng \\ Zhaoyang Li \\ Shuilin Wu \\ Zhenduo Cui \\ Shengli Zhu \\ Yanqin Liang \\ Xianjin Yang}

Tianjin Key Laboratory of Composite and Functional Materials, School of

Materials Science and Engineering,

Tianjin University, Tianjin, China
Correspondence: Zhaoyang Li

School of Materials Science and Engineering, Tianjin University,

135 Yaguan Road, Jinnan District,

Tianjin 300350, China

Email zyli@tju.edu.cn
Background: Calcium sulphate cement (CSC) is widely used as an osteoconductive biomaterial in bone repair and regeneration.

Purpose: In this study, porous $\mathrm{TiO}_{2}$ microspheres were added to CSC to achieve a controlled and sustained drug (gentamicin) release.

Methods: Scanning electron microscopy (SEM), transmission electron microscopy (TEM), X-ray powder diffraction (XRD), and Brunauer-Emmett-Teller (BET) surface area analysis were conducted to analyse the morphology, phase composition, and surface area of the $\mathrm{TiO}_{2}$ microspheres and composite cements. In addition, the injection time, compressive strength, degradation behaviour, and antibacterial ability of the composite cements were examined during in vitro degradation. Gentamicin release profile was recorded using an ultraviolet spectrophotometer. Results: The results revealed the excellent drug loading ability of the $\mathrm{TiO}_{2}$ microspheres. The addition of $\mathrm{TiO}_{2}$ microspheres improved the injectability and compressive strength of the composite cements, the maximum value of which was achieved at a $\mathrm{TiO}_{2}$ loading of $5 \mathrm{wt} \%$. When immersed in simulated body fluid (SBF), the composite cements doped with $\mathrm{TiO}_{2}$ microspheres were observed to release gentamicin in a stable and sustained manner, especially in the latter stages of in vitro degradation. During degradation, $\mathrm{CSC}$ doped with $\mathrm{TiO}_{2}$ microspheres exhibited a typical apatite-like behaviour. Further, antibacterial analysis showed that CSC doped with $\mathrm{TiO}_{2}$ microspheres exhibited long-term antibiotic activity.

Conclusion: Thus, as an effective sustained-release formulation material, $\mathrm{TiO}_{2}$ microspheres show a great potential for application in bone cements.

Keywords: $\mathrm{TiO}_{2}$, microsphere, calcium sulfate cement, sustained drug release, antibacterial ability

\section{Introduction}

Developments in the field of bone-filling materials have improved the chances of success for millions of patients facing surgery. In clinical applications, bone cements are one of the most widely used bone filling materials. ${ }^{1}$ However, post-operative infections and complications are still potent threats that delay healing after bone cement injection. ${ }^{2}$ Although the rate of infection in orthopedic surgery is fairly low (reported to be $1 \%-3 \%),{ }^{3-6}$ post-operative infections and complications can be very troublesome and often cause severe pain and loss of bone tissue; moreover, they may lead to the removal of implants, and thus, a second surgical operation. ${ }^{7}$ Current antibacterial therapies rely on the systematic administration of antibiotics. ${ }^{8}$ Gentamicin is a common broad-spectrum, thermostable antibiotic and is one of the most widely used compounds in clinical applications..$^{9,10}$ In order to avoid infection at the site of 
implantation, antibiotic-loaded bone cements have been developed. ${ }^{11}$ However, an instantaneous burst release of the antibiotic, most of which is loaded in the cement matrix, leads to a low antibacterial activity because the amount of antibiotic able to reach the surgical site would be too low. ${ }^{10,12}$ Therefore, developing a solution to curb the burst release of antibiotics is a topic of significant interest for researchers working on bone filling materials.

$\mathrm{TiO}_{2}$ is widely used in implantology due to its nontoxicity, hydrophilicity, low cost, and good stability. ${ }^{13-19}$ $\mathrm{TiO}_{2}$ microparticles are capable of delivering antibiotic molecules and the process of drug release has been reported and their kinetics analyzed. ${ }^{20}$ Several researchers have reported that $\mathrm{TiO}_{2}$ can be used to deliver antibiotics. Pawlik et al prepared anodic $\mathrm{TiO}_{2}$ nanotube layers for the co-delivery of ibuprofen and gentamicin. ${ }^{21}$ Flak et al synthesized ZnPc@ $\mathrm{TiO}_{2}$ nanotubes to deliver doxorubicin. ${ }^{22}$ In both these studies, coatings were deposited on the surfaces of titanium alloys, which hindered drug release from the composite cement system. Meanwhile, it has been postulated that antibiotic carriers should preferably have a porous microcosmic structure, which would help in drug loading and release via diffusion, thus effectively eliminating instant release and prolonging the drug release process. ${ }^{23-25}$ Therefore, porous $\mathrm{TiO}_{2}$ microspheres can be a promising sustained antibiotic media in bone cement composites.

Herein, novel porous $\mathrm{TiO}_{2}$ microspheres were designed to act as antibiotic carriers. Further, the relevance of compressive strength and injectable time of composite cements with $\mathrm{TiO}_{2}$ microspheres doping concentration was discussed; the degradation stability, drug release profile, surface morphology, phase transformation, and antibacterial properties of composite cements doped with $\mathrm{TiO}_{2}$ microspheres were investigated.

\section{Materials and methods Preparation of $\mathrm{TiO}_{2}$ microspheres}

Amorphous $\mathrm{TiO}_{2}$ microspheres were prepared by the hydrolysis of $\mathrm{Ti}\left(\mathrm{SO}_{4}\right)_{2}$ according to a previously reported method. ${ }^{26}$ A de-ionized solution of Ti $\left(\mathrm{SO}_{4}\right)_{2}(75 \mathrm{~mL}, 4 \mathrm{mmol})$ was mixed in $75 \mathrm{~mL}$ of 1-propanol along with $2.0 \mathrm{~g}$ of polyvinylpyrrolidone. The mixture was stirred in a beaker for 3 hours at $70^{\circ} \mathrm{C}$ and washed and aged in a $1 \mathrm{~mol} / \mathrm{L}$ alkaline solution. Subsequently, the precipitates were solvothermally treated in a stainless steel autoclave.

\section{Characterization of $\mathrm{TiO}_{2}$ microspheres}

$\mathrm{TiO}_{2}$ microspheres were mixed with gentamicin (Aladdin Co., Ltd, Shanghai, China) in de-ionized water by stirring and the wet mixture was dried at room temperature for 24 hours. Surfaces of the $\mathrm{TiO}_{2}$ microspheres were visualized by a scanning electron microscope (HITACHI S-4800, Tokyo, Japan) operating at an accelerating voltage of $5 \mathrm{kV}$ in the secondary electron imaging mode and by transmission electron microscopy (Philips Tecnai G2F20, Amsterdam, Netherlands) at an accelerating voltage of $200 \mathrm{kV}$. Phase analysis of the $\mathrm{TiO}_{2}$ microspheres was conducted using an $\mathrm{X}$-ray powder diffraction (XRD) instrument (RIGAKU/ DMAX $40 \mathrm{kV}, 200 \mathrm{~mA}, \mathrm{Cu} \mathrm{K} \alpha$ radiation, $\lambda=1.5418 \AA$ ). The Brunauer-Emmett-Teller (BET) surface areas of original $\mathrm{TiO}_{2}$ microspheres and gentamicin-loaded $\mathrm{TiO}_{2}$ microspheres were measured on a Micromeritics instrument (3Flex 577) using $\mathrm{N}_{2}$ adsorption/desorption isotherms. A dynamic light scattering (Malvern Zetasizer NANO-ZS90, Malvern, UK) was used to determine the zeta potential of original $\mathrm{TiO}_{2}$ microspheres and gentamicin-loaded $\mathrm{TiO}_{2}$ microspheres.

\section{Preparation of gentamicin/ $/ \mathrm{TiO}_{2}$-calcium sulfate cement $\left(\mathrm{G} / \mathrm{TiO}_{2}-\mathrm{CSC}\right)$}

Calcium sulfate (CS) has a long history of being used as a bone filling material owing to its advantageous features of a suitable setting time, good mechanical properties, and biodegradability. ${ }^{9,27}$ In this study, we chose CS as the bone cement matrix to be doped with $\mathrm{TiO}_{2}$ microspheres. The cement powder consisted of CS hemihydrate (analytical reagent [AR], 97.0\%; Aladdin). A total of $0.1875 \mathrm{~g}$ gentamicin and different weights ${ }^{28,29}$ of $\mathrm{TiO}_{2}$ (prepared by solvothermal synthesis) were dispersed by ultrasonication in $2.5 \mathrm{~mL}$ of de-ionized water as the liquid monomer. The doping concentration of $\mathrm{TiO}_{2}$ was determined by injection and compressive tests. The cement powder was mixed with the liquid monomer at a liquid:solid ratio of $0.5 \mathrm{~mL} / \mathrm{g}$ in a beaker to form a paste. Subsequently, the cement paste was injected through a $5 \mathrm{~mL}$ syringe into a polytetrafluoroethylene mold to fabricate cylindrical specimens for compressive testing and gentamicin antibiotic-elution assay. The liquid monomer without gentamicin was set as the control group.

\section{Characterization of $\mathrm{G} / \mathrm{TiO}_{2}-\mathrm{CSC}$}

Antibiotic release kinetics during in vitro degradation

Drug release studies were conducted by separately soaking each cylindrical specimen $(6 \mathrm{~mm}$ in diameter and $12 \mathrm{~mm}$ in height for compressive testing, $12 \mathrm{~mm}$ in diameter and $2 \mathrm{~mm}$ in height for antibacterial assay) in $5 \mathrm{~mL}$ of simulated body fluid (SBF) ${ }^{30}$ these specimens were then incubated at $37^{\circ} \mathrm{C}$ for 2 weeks in a shaking incubator. The SBF solution was drawn out at pre-defined time intervals $(1,3,5,7$, and 
14 days) to examine the quantity of gentamicin released. The measurement was carried out using an ultraviolet spectrophotometer (UV-2700220V CH) at a wavelength of $253 \mathrm{~nm} \cdot{ }^{31}$ To determine the cumulative release of gentamicin from different samples, a calibration curve was initially plotted using different concentrations of pristine gentamicin solution; the amount of drug released from the tested sample could then be calculated from the measured absorbance using the generated calibration equation.

\section{Mechanical properties and stability during in vitro degradation}

After the antibiotic release studies, the specimens were removed from the SBF solution and dried at $60^{\circ} \mathrm{C}$ in an oven for 24 hours. A universal testing machine was used to evaluate the compressive strength of the composite cement specimens; the weight loss in the specimens was measured using the following equation in which $\mathrm{W}_{0}$ refers to the initial weight and $\mathrm{W}_{\mathrm{t}}$ refers to the weight at time $\mathrm{t}$.

$$
\text { Weight loss }(\%)=\frac{\mathrm{W}_{0}-\mathrm{W}_{\mathrm{t}}}{\mathrm{W}_{0}} \times 100
$$

The $\mathrm{pH}$ value of the SBF solution from which the specimens were removed was measured using a $\mathrm{pH}$ meter.

\section{Morphology and phase analysis during in vitro degradation}

The surface morphology of the $\mathrm{G} / \mathrm{TiO}_{2}$-CSC specimens after in vitro degradation was observed using a scanning electron microscope and their composition was analyzed by energy dispersive X-ray analysis. The phase composition was determined by XRD.

\section{Antibacterial activity test}

The antibacterial activity of the $\mathrm{G} / \mathrm{TiO}_{2}-\mathrm{CSC}$ specimens was evaluated by the agar disc diffusion method. Escherichia coli and Staphylococcus aureus were individually inoculated in Luria-Bertani (LB) broth (liquid medium) $(5 \mathrm{~mL})$ and agitated overnight in a shaking incubator $\left(37^{\circ} \mathrm{C}, 220 \mathrm{rpm}\right)$. The concentration of the bacterial cells was measured by optical spectrometry at $600 \mathrm{~nm}$; it was calculated to be $10^{5}$ cells $/ \mathrm{mL}$. Subsequently, $50 \mu \mathrm{L}$ of the bacterial solution was inoculated on a plate of LB solid medium. Then specimens of $\mathrm{G} / \mathrm{TiO}_{2}-\mathrm{CSC}$ and G-CSC obtained from different degradation times (3, 7, 14 days) in "Antibiotic release kinetics during in vitro degradation" section were placed carefully on the bacteria inoculated agar surface. These agar plates were then incubated at $37^{\circ} \mathrm{C}$ for 24 hours. Subsequently, agar plates were taken out to observe the inhibition zones. The diameters of the inhibition zones were measured from the photographs of the agar plate, which were captured using a digital camera.

\section{Statistical analysis}

Quantitative data were processed with Origin 8.6 (Origin Lab Corporation, Northampton, MA, USA). All the experiments were repeated at least five times. A Student's $t$-test was used to compare the means of different specimens. Statistical significance was set at a CI of $>95 \%$ $(P<0.05)$.

\section{Result and discussion Characterization of the $\mathrm{TiO}_{2}$ microspheres}

The scanning electron microscopy (SEM) images of $\mathrm{TiO}_{2}$ microspheres are shown in Figure 1A. The top right inset presents a magnified image of the homologous main image. $\mathrm{TiO}_{2}$ microcrystals were observed to be homogeneous inerratic and well dispersed. The surfaces of the $\mathrm{TiO}_{2}$ microspheres were lychee-like and their diameter was in the range of $700-1,200 \mathrm{~nm}$, which is the aggregation state of $\mathrm{TiO}_{2}$
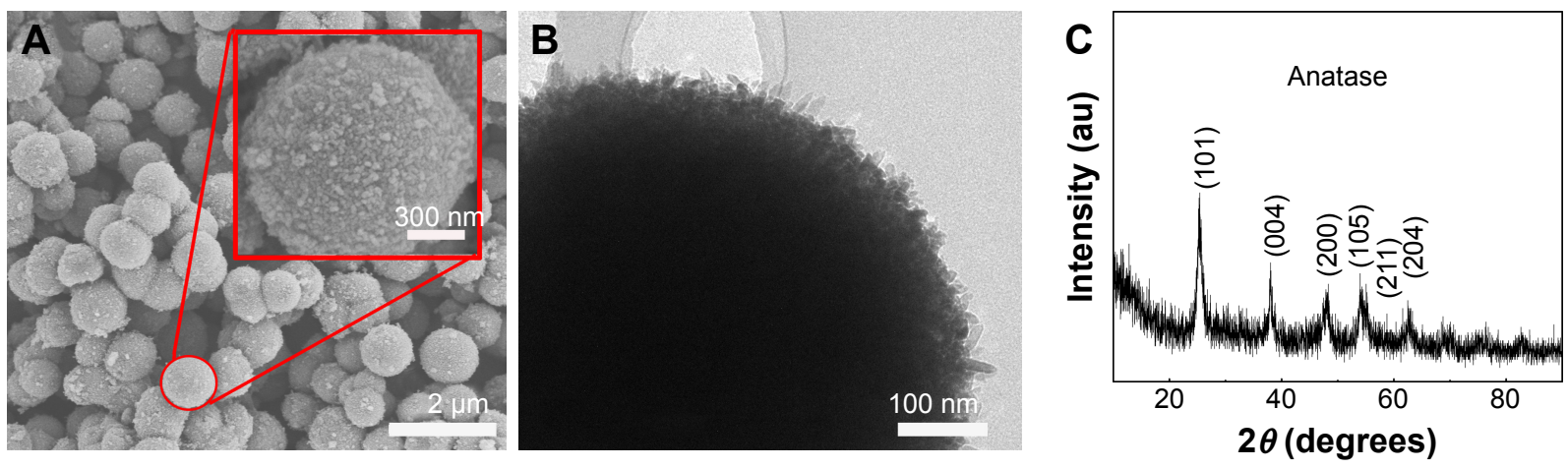

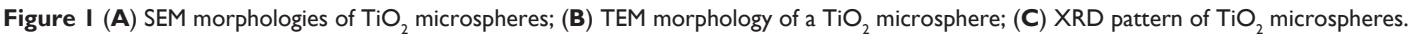
Abbreviations: SEM, scanning electron microscopy; TEM, transmission electron microscopy; $\mathrm{XRD}, \mathrm{X}$-ray powder diffraction. 
crystalline grain. Figure 1B shows the morphology of a single $\mathrm{TiO}_{2}$ microsphere, which indicates its highly porous nature. A large surface area plays an important role in achieving a high specific capacity, which can in turn provide high drug loading capacity. ${ }^{32}$ Figure $1 \mathrm{C}$ depicts the XRD pattern of $\mathrm{TiO}_{2}$ microspheres. The characteristic peaks are consistent with those of anatase $\mathrm{TiO}_{2}$ (JCPDS no. 21-1272).

The morphology of $\mathrm{TiO}_{2}$ microspheres loaded with gentamicin is shown in Figure 2. After immersion in gentamicin solution, the surface morphology of the $\mathrm{TiO}_{2}$ microspheres became much smoother, which indicates that gentamicin was loaded onto the surface micropores of $\mathrm{TiO}_{2}$ microspheres. The decrease in the surface microstructure proves the ability of $\mathrm{TiO}_{2}$ microspheres to load drugs.

Figure $3 \mathrm{~A}$ shows the $\mathrm{N}_{2}$ adsorption-desorption isotherms of the original $\mathrm{TiO}_{2}$ microspheres and $\mathrm{TiO}_{2}$ loaded with gentamicin; the curves depict type IV isotherms with a hysteresis loop at relative pressures $\left(\mathrm{P} / \mathrm{P}_{0}\right)$ of $0.4-0.8$ and $0.5-0.9$, respectively, which suggest capillary condensation in the micropores. Figure 3B shows the pore diameter distribution of the original $\mathrm{TiO}_{2}$ microspheres and the $\mathrm{TiO}_{2}$ microspheres loaded with gentamicin. No peaks corresponding to micropores could be observed. The BET surface areas of $\mathrm{TiO}_{2}$ before and after loading with gentamicin were $241.4678 \mathrm{~m}^{2} / \mathrm{g}$ and $181.0672 \mathrm{~m}^{2} / \mathrm{g}$, respectively. The microspheres had a larger pore volume and a relatively larger BET surface area. Because the gentamycin molecules were approximately $5 \AA$ in width and $10 \AA$ in length, ${ }^{33}$ the pores on the surface of $\mathrm{TiO}_{2}$ microspheres were large enough to accommodate them. Therefore, the reduced surface area of the microspheres could be attribute to the loading with gentamycin.

The drug release performance of a drug delivery system depends strongly on its morphology. ${ }^{21} \mathrm{TiO}_{2}$ microspheres with a nanoporous structure have a significant influence on the drug release profile. The BET results showed that $\mathrm{TiO}_{2}$ microspheres are porous in nature; these pores can be used to load antibiotics. The adsorption process of gentamicin was further characterized by determining the change in zeta potential values of gentamycin loaded $\mathrm{TiO}_{2}$ microspheres. As shown in Figure $3 \mathrm{C}$, the average zeta potential of $\mathrm{TiO}_{2}$ microspheres was $-32.9 \mathrm{mV}$, while it turned to positive values $(+12 \mathrm{mV})$ when the gentamycin was loaded. The observations indicated the electrostatic interaction between the positively charged gentamycin and the negative surface of $\mathrm{TiO}_{2}$ microspheres. The large surface area and pore diameter of $\mathrm{TiO}_{2}-\mathrm{CSC}$ provide more suitable conditions for hosting and controlled release gentamicin compared to the original CSC. Gentamicin molecules were embedded in that cement matrix, thus, they could easily be eluted away which resulted in a burst release when the cement was placed in SBF.

The Fourier-transform infrared spectra of samples were characteristic of $\mathrm{TiO}_{2}$ and gentamicin $\mathrm{TiO}_{2}$ compound, as shown in Figure 4A. In the graph, compounds with gentamicin exhibited absorption bands between 1,550 and $1,645 \mathrm{~cm}^{-1}$, which can be attributed to the bending of $\mathrm{N}-\mathrm{H}$ bond of the primary and secondary amines of gentamicin. The bands between 1,100 and 1,200 $\mathrm{cm}^{-1}$ were assigned to the stretching vibration of C-O-C of gentamicin. The broad absorption band around $600 \mathrm{~cm}^{-1}$ is due to the stretching vibrations of Ti-O-Ti and Ti-O bonds that are characteristic of the formation of a Ti-O-Ti network. The results corresponded with Raman spectra, as shown in Figure 4B. The bands of Ti-O-Ti were observed apparently between 143 and $608 \mathrm{~cm}^{-1}$ and compounds also showed the characteristic peaks of gentamicin, which could prove the successful combination of $\mathrm{TiO}_{2}$ microspheres and gentamicin.
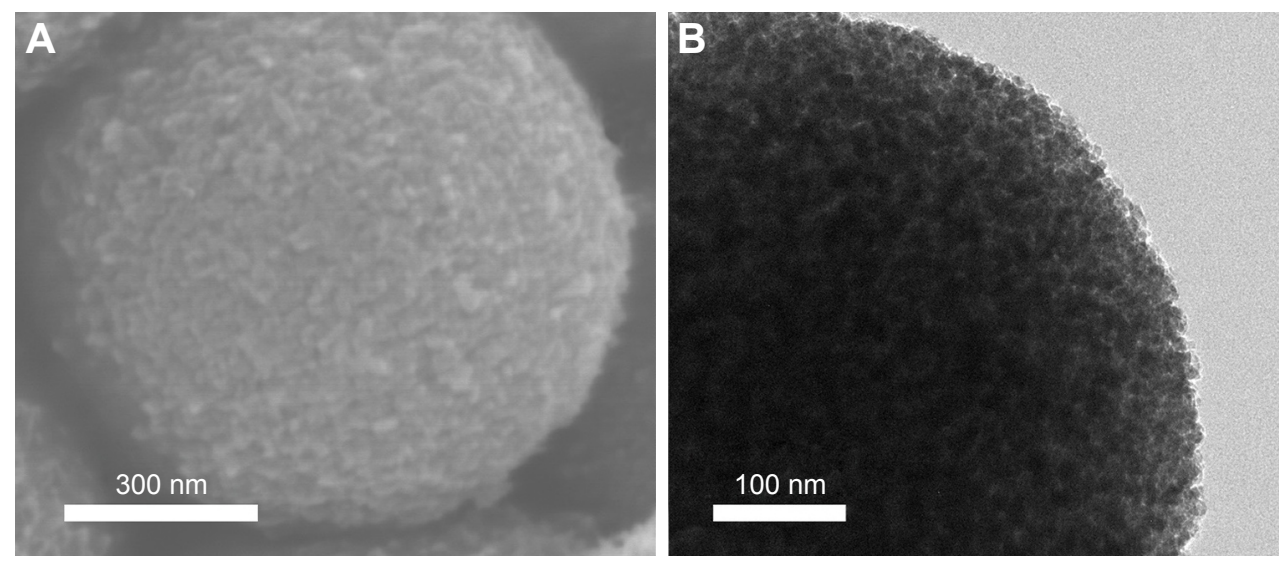

Figure 2 (A) SEM morphology and (B) TEM morphology of a $\mathrm{TiO}_{2}$ microsphere loaded gentamicin. Abbreviations: SEM, scanning electron microscopy; TEM, transmission electron microscopy. 

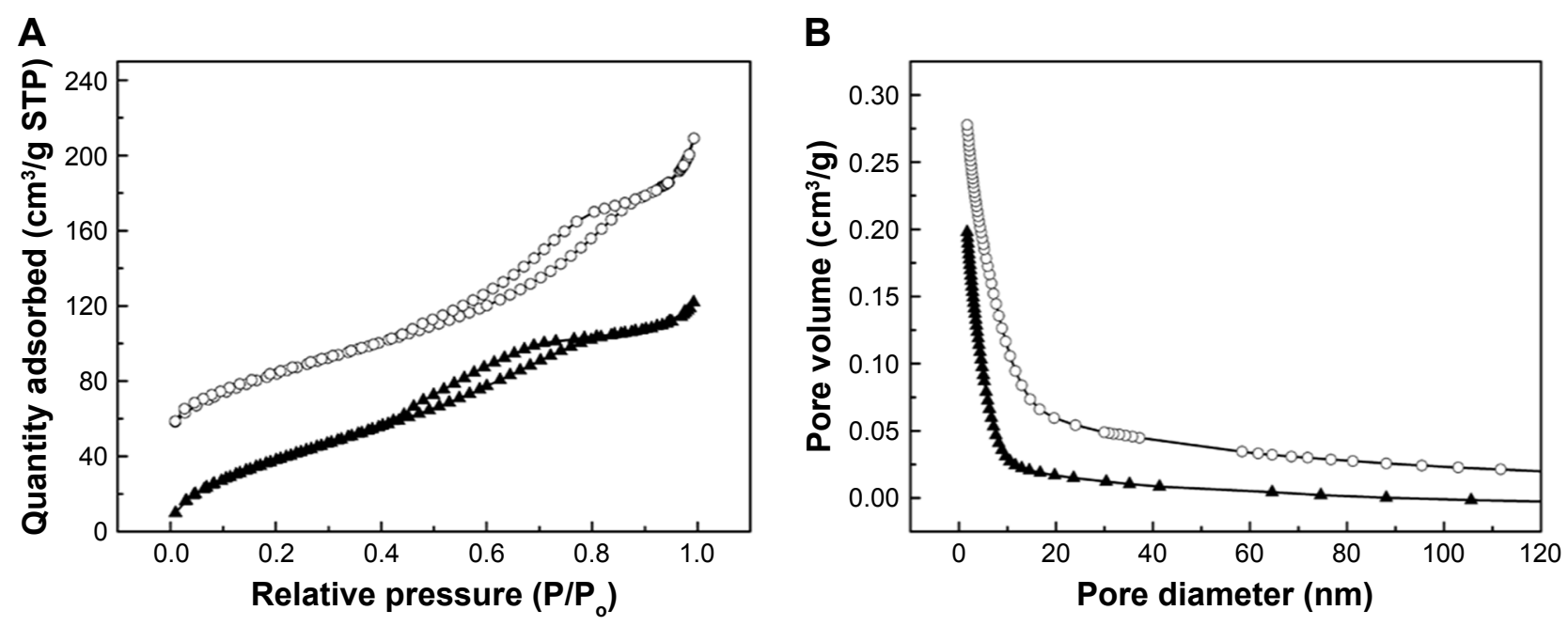

Relative pressure $\left(P / P_{0}\right)$

$\multimap-\mathrm{TiO}_{2} \multimap \mathrm{G} / \mathrm{TiO}_{2}$

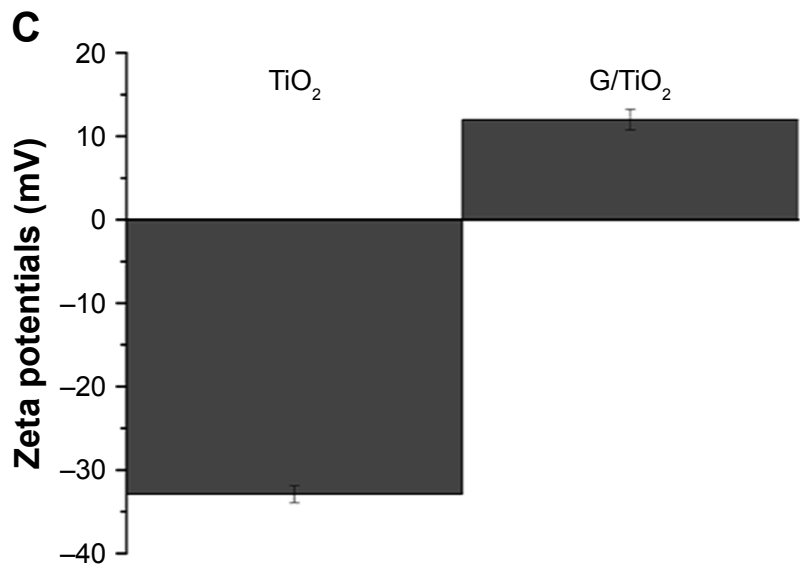

Figure $3(\mathbf{A}) \mathrm{N}_{2}$ adsorption-desorption isotherms; (B) pore size distribution; and (C) zeta potentials of $\mathrm{TiO}_{2}$ before and after being loaded with gentamicin. Abbreviations: $\mathrm{G} / \mathrm{TiO}_{2}$, gentamicin $/ \mathrm{TiO}_{2}$; STP, standard temperature and pressure.

A

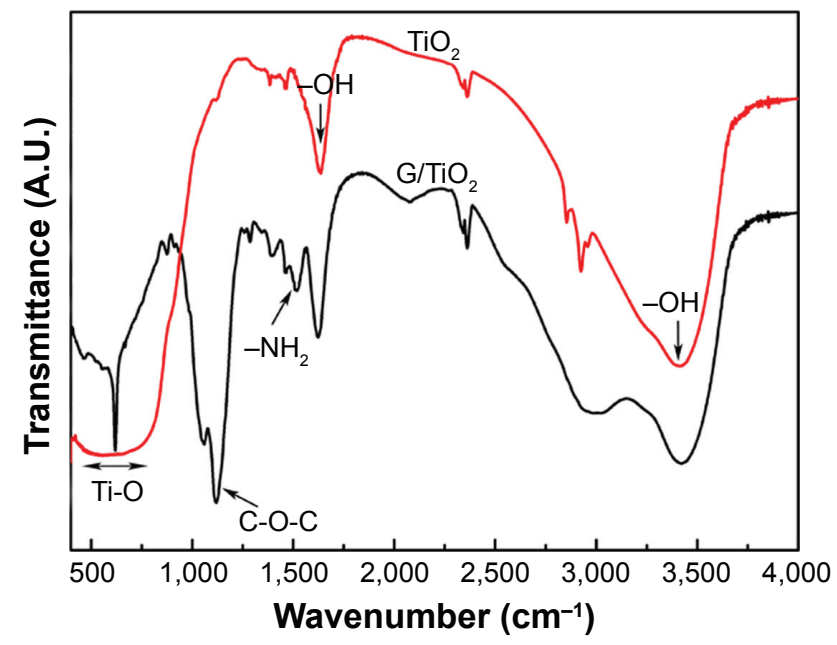

B

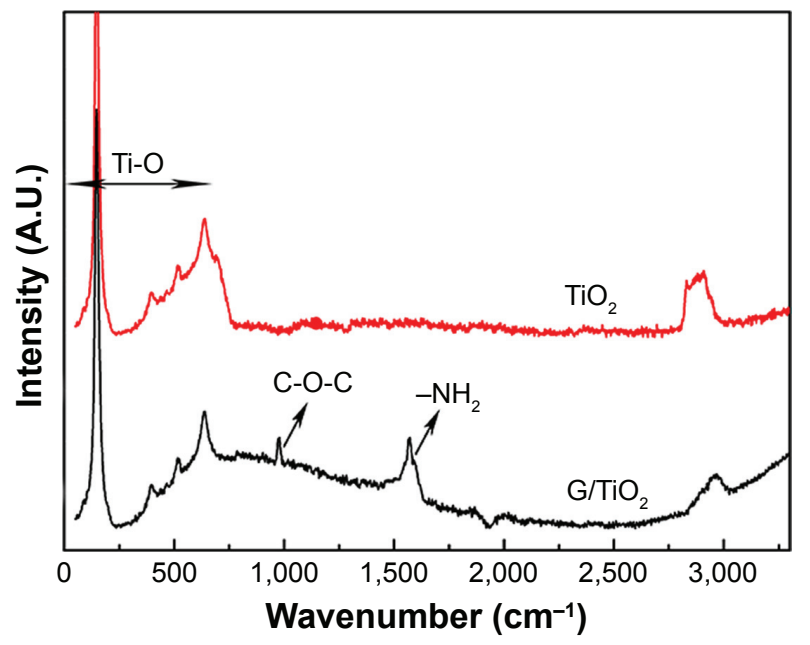

Figure 4 (A) FT-IR spectra and (B) Raman spectra of $\mathrm{TiO}_{2}$ before and after being loaded with gentamicin. Abbreviations: A.U., absorbance unit; FT-IR, Fourier-transform infrared; $\mathrm{G} / \mathrm{TiO}_{2}$, gentamicin/TiO ${ }_{2}$. 


\section{Characterization of $\mathrm{G} / \mathrm{TiO}_{2}-\mathrm{CSC}$}

Figure $5 \mathrm{~A}$ shows the mechanical properties of $\mathrm{TiO}_{2}-\mathrm{CSC}$ specimens with different $\mathrm{TiO}_{2}$ concentrations, while Figure 5B shows the variation in their injectability at different $\mathrm{TiO}_{2}$ concentrations. The compressive strength and injection time both followed the same trend. They initially increased with an increase in the $\mathrm{TiO}_{2}$ content but gradually decreased at $\mathrm{TiO}_{2}$ concentrations greater than $5 \%$. When the $\mathrm{TiO}_{2}$ content reached $5 \%, \mathrm{TiO}_{2}-\mathrm{CSC}$ exhibited the optimum compressive strength (13-14 MPa), which is almost twice as large as that of the control group without $\mathrm{TiO}_{2}$. Additionally, $\mathrm{TiO}_{2}-\mathrm{CSC}$ with $5 \% \mathrm{TiO}_{2}$ concentration exhibited the maximum injection time for different samples (5-6 minutes), which is suitable in clinical applications for lengthening the operation time. The $\mathrm{TiO}_{2}$ replacement of cement can accelerate the hydration rate of CSC which can increase the compressive strength. It is known that sulfate ions could dissolve into the mixing water and affect the hydration of cement. ${ }^{34}$ The incorporation of $\mathrm{TiO}_{2}$ accelerates the hydration rate of CSC, which can increase the compressive strength. However, when it was $5 \%$, the compressive strength reached the maximum. More $\mathrm{TiO}_{2}$ would induce the generation of defects and weak points due to the aggregation of $\mathrm{TiO}_{2}$ microspheres. ${ }^{35}$ What is more, the $\mathrm{TiO}_{2}$ inclusion in the cement causes a dilution effect, which could contribute to the delayed injection time. But for the cases over 5\%, the decrease of injection time may be attributed to a mass of $\mathrm{TiO}_{2}$ microspheres interacting together to form a 3D-network. ${ }^{36}$ Thus, it can be used as a good bioactive ingredient and reinforcing agent in bone composite cements. On the basis of these results, a $\mathrm{TiO}_{2}$ concentration of $5 \%$ was chosen to conduct the subsequent drug release experiments.

\section{In vitro drug release studies}

Figure 6A displays the cumulative gentamicin release profiles of the experimental group (with $\mathrm{TiO}_{2}$ ) and the control group (without $\mathrm{TiO}_{2}$ ). It was found that the cumulative gentamicin release curve of G-CSC had a biphasic profile, with a fast initial release followed by a continuous and slow release. In contrast to the control group, the cumulative gentamicin release curve of $\mathrm{G} / \mathrm{TiO}_{2}-\mathrm{CSC}$ was relatively sustainable and efficient. In the first stage of degradation ( $<1$ week), the cumulative release from the experimental group was lower than that from the control group. They reached an approximate standard after approximately 7-10day degradation. In the long run, the cumulative release from the experimental group (approximately 70\%) was higher than that of the control group (approximately 65\%). The absorption of gentamicin on $\mathrm{TiO}_{2}$ contributed to the slow release in the initial stage. In the following stage, the relatively faster release of gentamicin was mainly dependent on the incorporation of $\mathrm{TiO}_{2}$ in the cement matrix, which may form effective diffusion network pathways to encourage SBF penetration and dissolve gentamicin deep within the composite cement network, as reported previously. ${ }^{37}$ The initial burst release of gentamicin can be a consequence of the presence of gentamicin on the surface of the composites. When it comes to $\mathrm{G} / \mathrm{TiO}_{2}-\mathrm{CSC}$, the adsorption of $\mathrm{TiO}_{2}$ microspheres reduces the instantaneous burst release of gentamicin. The subsequent gentamicin release of $\mathrm{G} / \mathrm{TiO}_{2}-$ CSC comes from bulk diffusion and $\mathrm{TiO}_{2}$ microspheres. According to Figure 6B, G-CSC and $\mathrm{G} / \mathrm{TiO}_{2}-\mathrm{CSC}$ had similar trends of weight loss. Because there was non-degradable $\mathrm{TiO}_{2}$ microspheres in $\mathrm{G} / \mathrm{TiO}_{2}-\mathrm{CSC}$, the net weight loss of

\section{B}

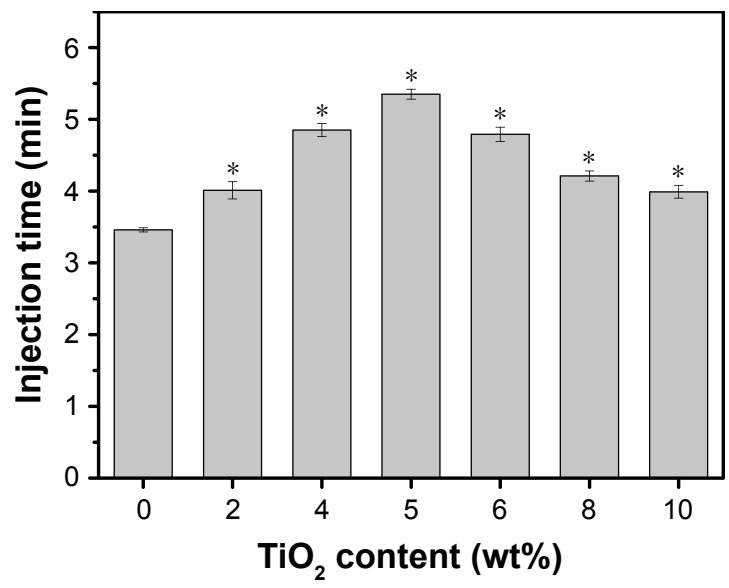

Figure 5 (A) Compressive strength and (B) injection time of $\mathrm{TiO}_{2}-\mathrm{CSC}$ with different $\mathrm{TiO}_{2}$ concentrations.

Note: $* P<0.05$.

Abbreviation: CSC, calcium sulfate cement. 

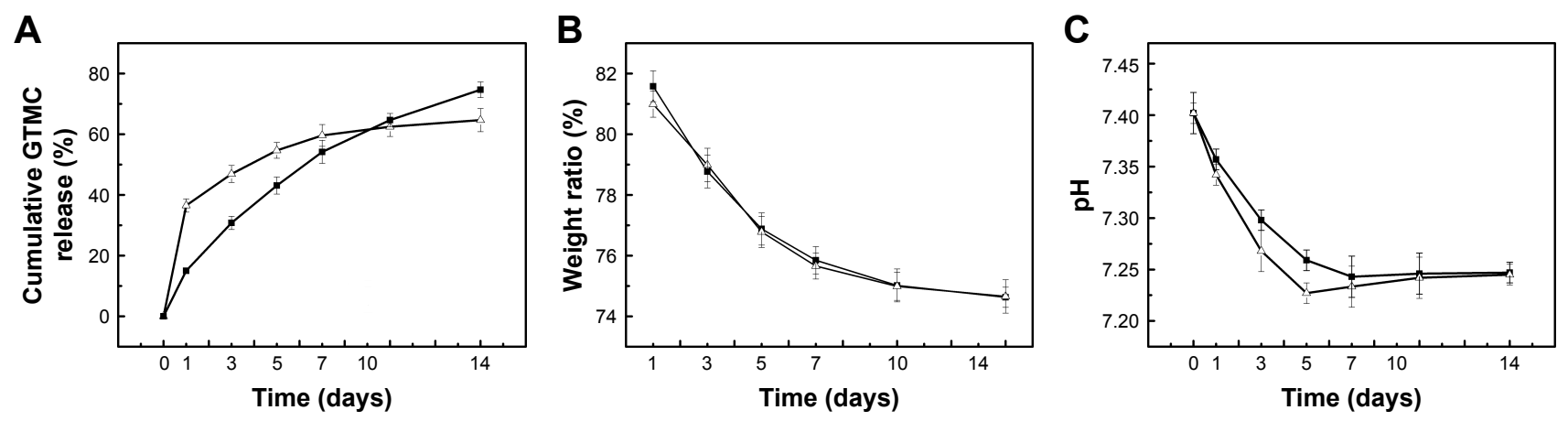

$\rightarrow \mathrm{G} / \mathrm{TiO}_{2}-\mathrm{CSC} \longrightarrow \mathrm{G}-\mathrm{CSC}$

Figure 6 Cumulative gentamicin release profile (A), weight loss (B), and pH change $(\mathbf{C})$ of the different samples soaking in the SBF for different times. Abbreviations: GTMC, gentamicin; $\mathrm{G} / \mathrm{TiO}_{2}-\mathrm{CSC}$, gentamicin/ $/ \mathrm{TO}_{2}$-calcium sulfate cement; $\mathrm{SBF}$, simulated body fluid.

calcium sulfate matrix in $\mathrm{G} / \mathrm{TiO}_{2}-\mathrm{CSC}$ was higher than that in G-CSC. It may be attributed to the weak points formed by $\mathrm{TiO}_{2}$ aggregation, which accelerates the degradation of calcium sulfate. Thus, there was more gentamicin release in $\mathrm{G} / \mathrm{TiO}_{2}-\mathrm{CSC}$ and the subsequent efficient release was reported to improve the rate of healing in the extended period. ${ }^{38}$ The antibacterial activity of $\mathrm{G} / \mathrm{TiO}_{2}-\mathrm{CSC}$ was weaker than that of G-CSC during the post-operative relief period, which can be attributed to the porous structure of $\mathrm{TiO}_{2}$ microspheres.

Weight loss of the composite cements with/without $\mathrm{TiO}_{2}$ during degradation is shown in Figure 6B. The weight loss increased with an increase in the extent of composite cement degradation; both composite cements (with/without $\mathrm{TiO}_{2}$ ) had the same tendency of a slightly slow rate of degradation. When the samples were soaked in SBF for 2 weeks, the weight loss was approximately $25 \%$. This result was in agreement with other previous studies about degradation rate of bone cement. ${ }^{39}$ There was no significant difference in the degradation profile of $\mathrm{G} / \mathrm{TiO}_{2}-\mathrm{CSC}$ and $\mathrm{G}-\mathrm{CSC}$, which indicated that the difference of gentamicin release was attributed to $\mathrm{TiO}_{2}$ microspheres. Figure $6 \mathrm{C}$ shows the changes in the $\mathrm{pH}$ of the composite cements (with/without $\mathrm{TiO}_{2}$ ) soaked in SBF for different time periods. The $\mathrm{pH}$ decreased during the first five days of immersion, after which it exhibited a small increase. G-CSC has a relatively lower $\mathrm{pH}$ value because of the amount of gentamicin released in an initial burst. As the degradation process continued, $\mathrm{pH}$ values of both reached an equilibrium state in the range of 7.2-7.4. Cement $\mathrm{pH}$ is an important factor controlling calcium and phosphorus concentrations in the cement solution. In this range, it won't change body fluid environment (7-7.4) or induce aseptic inflammation, which is caused by a low $\mathrm{pH}$ value of the body fluid environment, can be avoided..$^{40}$ It is also relevant to bone metabolic pro- cess; a relatively low $\mathrm{pH}$ is ill-suited to bone metabolism and mineralization. ${ }^{41}$

\section{Morphology of composite cements during in vitro drug release}

Figure 7 shows the surface morphology and composition of composite cements. Figure 7A-H reveals the variation in the morphology of $\mathrm{G} / \mathrm{TiO}_{2}-\mathrm{CSC}$ and $\mathrm{G}-\mathrm{CSC}$ when subjected to degradation in SBF. Calcium sulfate dihydrate has a blockshaped crystal structure ${ }^{42}$ such structures are evident in the matrix and the $\mathrm{TiO}_{2}$ microspheres are depicted by red dotted circles. These microspheres, which were approximately $700-800 \mathrm{~nm}$ in diameter, were dispersed homogeneously in the cement matrix (Figure $7 \mathrm{E}-\mathrm{H}$ ). In contrast, there were only block-shaped structures in Figure 7A-D. The surface morphology of the composite cements exhibited a gradual change with an increase in the extent of degradation. At higher degradation times, the composite cements with $\mathrm{TiO}_{2}$ exhibited more obvious changes. The amount of bonelike apatite remarkably increased and after a week of soaking in SBF, an apatite layer was formed on the surface. In the latter stages of degradation, the loose apatite surface provided a more bioactive environment for tissue cell attachment and growth. Figure $7 \mathrm{E}-\mathrm{H}$ shows that the degradation rate of $\mathrm{TiO}_{2}$ microspheres was slower than that of calcium sulfate dihydrate. Thus, $\mathrm{TiO}_{2}$ microspheres can persistently control the release of gentamicin, especially in the latter stages after the implantation of composite cements.

\section{Phase of composite cements during in vitro drug release}

Figure 8 depicts the XRD patterns of G-CSC and $\mathrm{G} / \mathrm{TiO}_{2}$ CSC after soaking in SBF for different degradation times ( 1 day, 3 days, 7 days, and 14 days). The peaks at $25.4^{\circ}, 37.8^{\circ}$, and $48.0^{\circ}$, which correspond to the structure of anatase $\mathrm{TiO}_{2}$, 

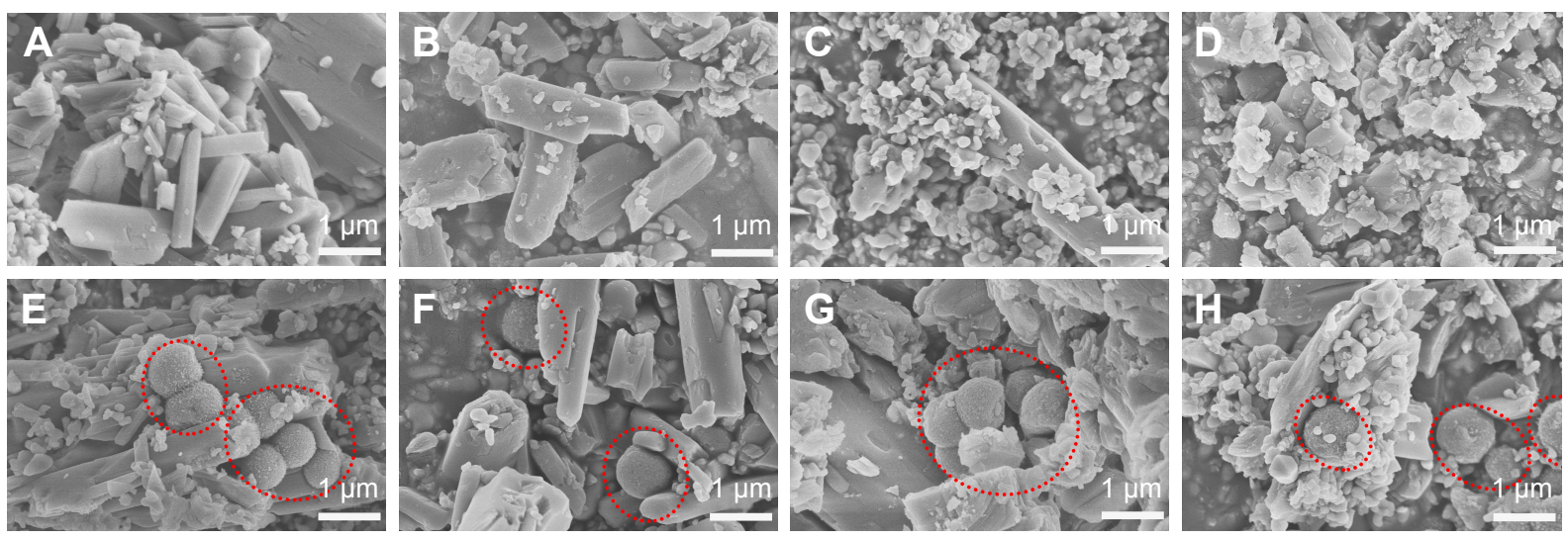

Figure 7 SEM representative images of G-CSC during different degradation times (A: I day, B: 3 days, C: 7 days, D: 14 days) and G/TiO - -CSC during different degradation times (E: I day, $\mathbf{F}: 3$ days, $\mathbf{G}: 7$ days, $\mathbf{H}$ : 14 days).

Note: $\mathrm{TiO}_{2}$ microspheres were depicted by red dotted circles.

Abbreviations: SEM, scanning electron microscopy; G-CSC, gentamicin-calcium sulfate cement; G/TiO ${ }_{2}$, gentamicin/TiO .

can be seen in Figure 8A. The peaks at $11.6^{\circ}, 20.7^{\circ}, 29.1^{\circ}$, and $31.1^{\circ}$, which were found both in G-CSC and $\mathrm{G} / \mathrm{TiO}_{2}$ CSC before soaking in SBF, correspond to the structure of calcium sulfate dehydrate (gypsum) according to JCPDS no 33-0311. As can be seen in the figure, the half-peak width of the characteristic peaks $\left(11.6^{\circ}, 20.7^{\circ}\right.$, and $\left.29.1^{\circ}\right)$ increased, which indicated a decrease in the degree of crystallinity of the samples. With an increase in the degradation time, the structure and phase obviously changed. After the samples were soaked in SBF for 2 weeks, the characteristic peaks $\left(11.6^{\circ}, 23.4^{\circ}\right.$, and $\left.29.2^{\circ}\right)$ indicated phosphate (brushite) (JCPDS no. 09-0077). The addition of $\mathrm{TiO}_{2}$ microspheres had little influence on the peak position but enhanced the peak intensity.

The XRD patterns (Figure 8) were analyzed along with the SEM images (Figure 7). According to the structure and phase of the specimens, they were found to be phosphate (brushite) in the latter stages of degradation; through SEM, the specimens were found to have a loose apatite morphology. During the degradation of calcium sulfate dehydrate, $\mathrm{Ca}^{2+}$ combined with the phosphate groups in SBF to form a loose phosphate precipitate (brushite). ${ }^{43}$ Brushite displays a high resorption rate when used as a bone composite cement and shows excellent biocompatibility and integration with the surrounding tissue. ${ }^{44-47}$ Thus, the addition of $\mathrm{TiO}_{2}$ microspheres promoted degradation and enhanced the osteoconductive and osteoinductive properties of composite cements.

\section{Antibiotic activity}

Figure 9A shows the results of antibiotic assay of all the samples after different degradation times ( 3 days, 7 days, and 14 days). The diameter of the samples was approximately $12 \mathrm{~mm}$. Figure $9 \mathrm{~B}$ and $\mathrm{C}$ shows the diameters of the inhibition zones of G-CSC and $\mathrm{G} / \mathrm{TiO}_{2}-\mathrm{CSC}$ cultivated in two
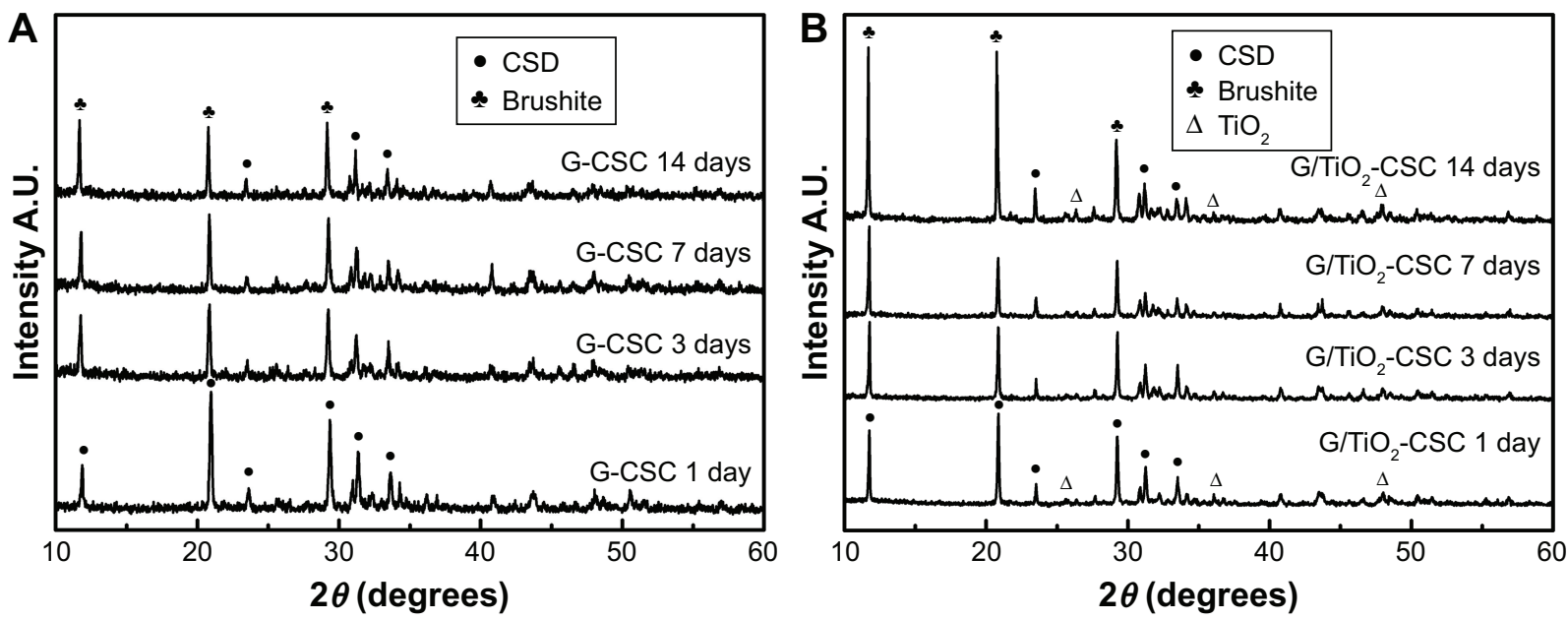

Figure 8 XRD of G-CSC (A) and G/TiO $-\mathrm{CSC}$ (B) during different degradation times (I day, 3 days, 7 days, 14 days).

Abbreviations: A.U., absorbance unit; CSD, calcium sulfate dihydrate; XRD, X-ray powder diffraction; G-CSC, gentamicin-calcium sulfate cement. 
A
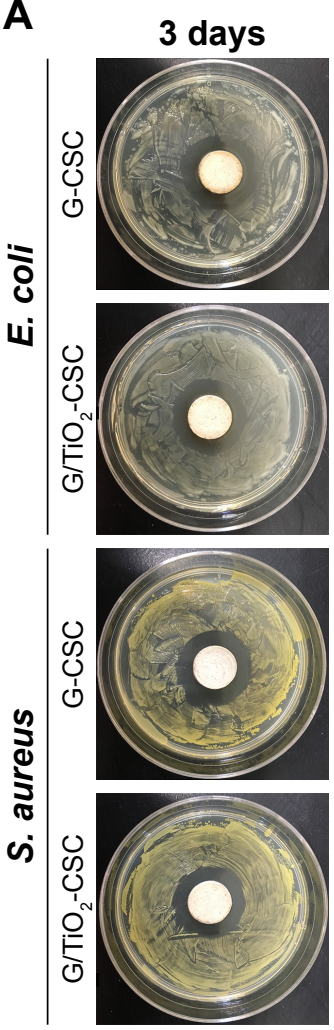

7 days
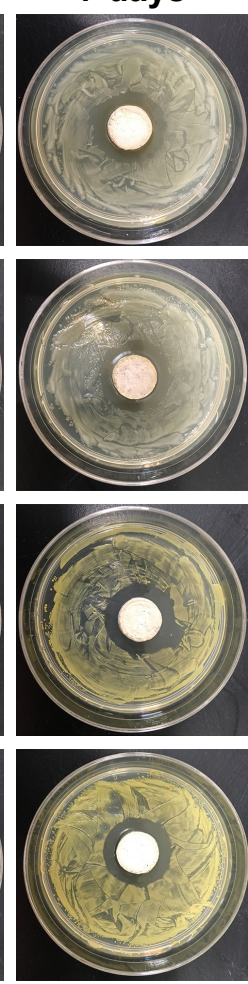

14 days
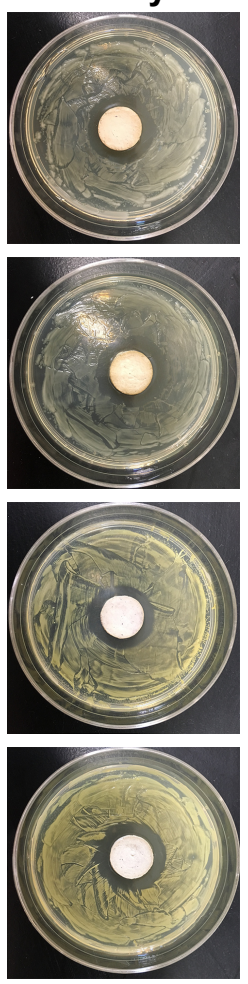

B
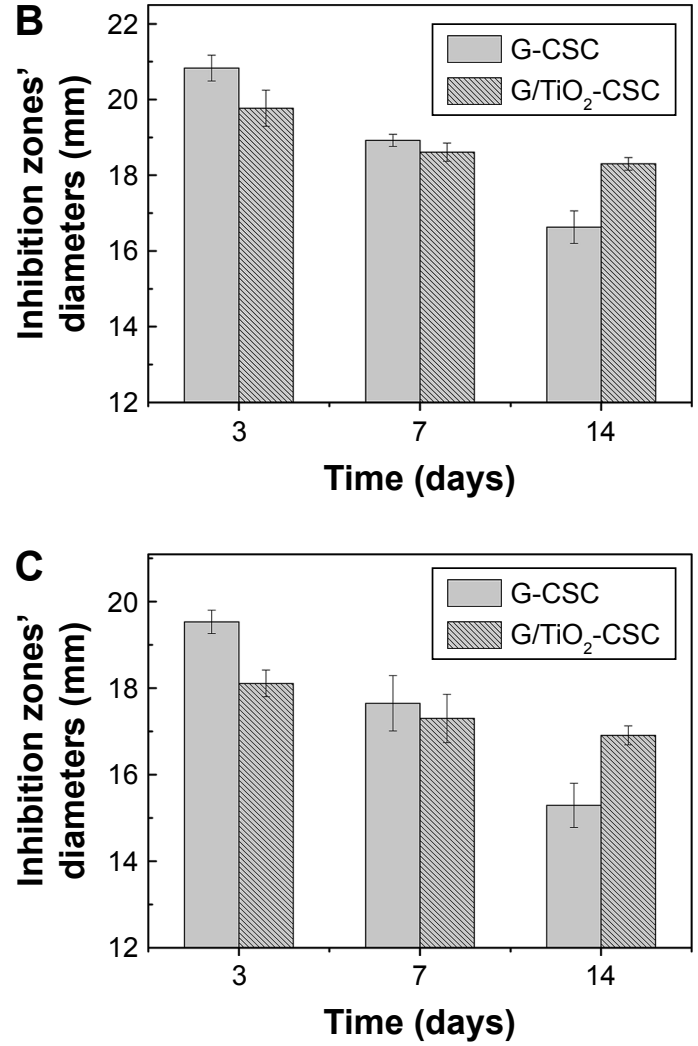

Figure 9 (A) Antibiotic activity of the G-CSC and G/TiO $-\mathrm{CSC}$; (B) inhibition zones' diameters of Escherichia coli and (C) Staphylococcus aureus of different samples. Abbreviations: G-CSC, gentamicin-calcium sulfate cement; $\mathrm{G} / \mathrm{TiO}_{2}$, gentamicin/ $\mathrm{TiO}_{2}$.

different bacterial strains. From the figure, we can see that the diameters of the inhibition zones against $S$. aureus were generally larger than those against $E$. coli. This is because gentamicin is more effective against gram-positive bacterial strains, such as $S$. aureus. ${ }^{48}$ The results indicate that with an increase in SBF soaking time, the quantity of released gentamicin increased and the inhibition zones became smaller. During the first week of degradation, the inhibition zones of $\mathrm{G} / \mathrm{TiO}_{2}-\mathrm{CSC}$ were smaller than those of G-CSC. In the next week, the inhibition zones of $\mathrm{G} / \mathrm{TiO}_{2}-\mathrm{CSC}$ gradually became larger than those of G-CSC. According to the gentamicin release profile, in the beginning of drug diffusion (1 week), specimens of G-CSC had an initial burst rather than $\mathrm{G} / \mathrm{TiO}_{2}$ CSC. Thus, G-CSC specimens released more gentamicin than $\mathrm{G} / \mathrm{TiO}_{2}-\mathrm{CSC}$ specimens and caused the bigger inhibition zones. Conversely, the inhibition zones of $\mathrm{G} / \mathrm{TiO}_{2}-\mathrm{CSC}$ were bigger than those of G-CSC at day 7, which may be due to the subsequent efficient gentamicin diffusion of $\mathrm{G} / \mathrm{TiO}_{2}-\mathrm{CSC}$ from bulk diffusion and $\mathrm{TiO}_{2}$ microspheres contained. The rate of gentamicin release of $\mathrm{G} / \mathrm{TiO}_{2}-\mathrm{CSC}$ was lower in the beginning and then the enhanced antibacterial ability may have been due to the sustained release in the next stage. Also, $\mathrm{TiO}_{2}$ is known to have antibacterial ability, so it may have a synergistic antibacterial effect together with gentamicin.

\section{Conclusion}

Porous $\mathrm{TiO}_{2}$ microspheres were synthesized using a solvothermal method and added to CSCs to achieve a sustained and controlled drug (gentamicin) release performance. The $\mathrm{TiO}_{2}$ microspheres exhibited a porous surface morphology and a high drug loading ability. The addition of $\mathrm{TiO}_{2}$ microspheres improved the injectability and compressive strength of the composite cements (maximum at $5 \mathrm{wt} \%$ $\mathrm{TiO}_{2}$ ). When immersed in $\mathrm{SBF}, \mathrm{TiO}_{2}$ microsphere-doped composite cements were observed to exhibit a sustained and stable gentamicin release performance, especially in the latter stages of in vitro degradation. The $\mathrm{TiO}_{2}$ microsphere-doped composite cements exhibited a typical apatite behavior and maintained a relatively stable SBF environment during degradation in SBF. Meanwhile, the $\mathrm{TiO}_{2}$ microsphere-doped composite cements exhibited long-term antibiotic properties, as evidenced by the results of disc diffusion analysis. These results indicate that $\mathrm{TiO}_{2}$ microspheres can be used as an effective sustained-release formulation material in bone cements.

\section{Acknowledgment}

This work was financially supported by National Natural Science Foundation of China (grant no. 31570970). 


\section{Disclosure}

The authors report no conflicts of interest in this work.

\section{References}

1. Liu F-H. Synthesis of bioceramic scaffolds for bone tissue engineering by rapid prototyping technique. J Solgel Sci Technol. 2012;64(3): 704-710.

2. Ter Boo GJ, Grijpma DW, Moriarty TF, Richards RG, Eglin D. Antimicrobial delivery systems for local infection prophylaxis in orthopedicand trauma surgery. Biomaterials. 2015;52:113-125.

3. Harris WH, Sledge CB. Total hip and total knee replacement (2). N Engl J Med. 1990;323(12):801-807.

4. Shi Z, Neoh KG, Kang ET, Wang W. Antibacterial and mechanical properties of bone cement impregnated with chitosan nanoparticles. Biomaterials. 2006;27(11):2440-2449.

5. Kurtz SM, Lau E, Watson H, Schmier JK, Parvizi J. Economic burden of periprosthetic joint infection in the United States. J Arthroplasty. 2012;27(8 Suppl):61-65.

6. Setyawati MI, Kutty RV, Tay CY, Yuan X, Xie J, Leong DT. Novel theranostic DNA nanoscaffolds for the simultaneous detection and killing of Escherichia coli and Staphylococcus aureus. ACS Appl Mater Interfaces. 2014;6(24):21822-21831.

7. Campoccia D, Montanaro L, Arciola CR. The significance of infection related to orthopedic devices and issues of antibiotic resistance. Biomaterials. 2006;27(11):2331-2339.

8. Monteiro N, Martins M, Martins A, et al. Antibacterial activity of chitosan nanofiber meshes with liposomes immobilized releasing gentamicin. Acta Biomater. 2015;18:196-205.

9. Chen Z, Kang L, Meng QY, et al. Degradability of injectable calcium sulfate/mineralized collagen-based bone repair material and its effect on bone tissue regeneration. Mater Sci Eng C Mater Biol Appl. 2014;45: 94-102.

10. Naraharisetti PK, Lew MD, Fu YC, Lee DJ, Wang CH. Gentamicinloaded discs and microspheres and their modifications: characterization and in vitro release. $J$ Control Release. 2005;102(2):345-359.

11. Moskowitz JS, Blaisse MR, Samuel RE, et al. The effectiveness of the controlled release of gentamicin from polyelectrolyte multilayers in the treatment of Staphylococcus aureus infection in a rabbit bone model. Biomaterials. 2010;31(23):6019-6030.

12. Silverman LD, Lukashova L, Herman OT, Lane JM, Boskey AL. Release of gentamicin from a tricalcium phosphate bone implant. J Orthop Res. 2007;25(1):23-29.

13. Aw MS, Simovic S, Addai-Mensah J, Losic D. Polymeric micelles in porous and nanotubular implants as a new system for extended delivery of poorly soluble drugs. J Mater Chem. 2011;21(20):7082.

14. Aw MS, Gulati K, Losic D. Controlling Drug Release from Titania Nanotube Arrays Using Polymer Nanocarriers and Biopolymer Coating. J Biomater Nanobiotechnol. 2011;2(5):477-484.

15. Aw MS, Losic D. Ultrasound enhanced release of therapeutics from drug-releasing implants based on titania nanotube arrays. Int J Pharm. 2013;443(1-2):154-162.

16. Kumeria T, Mon H, Aw MS, et al. Advanced biopolymer-coated drug-releasing titania nanotubes (TNTs) implants with simultaneously enhanced osteoblast adhesion and antibacterial properties. Colloids Surf B Biointerfaces. 2015;130:255-263.

17. Chao CS, Liu KH, Tung WL, Chen SY, Liu DM, Chang YP. Bioactive $\mathrm{TiO} 2$ ultrathin film with worm-like mesoporosity for controlled drug delivery. Microporous Mesoporous Mater. 2012;152:58-63.

18. Gulati K, Aw MS, Findlay D, Losic D. Local drug delivery to the bone by drug-releasing implants: perspectives of nano-engineered titania nanotube arrays. Ther Deliv. 2012;3(7):857-873.

19. Lee DW, Yun YP, Park K, Kim SE. Gentamicin and bone morphogenic protein-2 (BMP-2)-delivering heparinized-titanium implant with enhanced antibacterial activity and osteointegration. Bone. 2012;50(4): 974-982.
20. Dash S, Murthy PN, Nath L, Chowdhury P. Kinetic modeling on drug release from controlled drug delivery systems. Acta Pol Pharm. 2010; 67(3):217.

21. Pawlik A, Jarosz M, Syrek K, Sulka GD. Co-delivery of ibuprofen and gentamicin from nanoporous anodic titanium dioxide layers. Colloids Surf B Biointerfaces. 2017;152:95-102.

22. Flak D, Yate L, Nowaczyk G, Jurga S. Hybrid ZnPc@TiO nanostructures for targeted photodynamic therapy, bioimaging and doxorubicin delivery. Mater Sci Eng C Mater Biol Appl. 2017;78:1072-1085.

23. Gupta P, Vermani K, Garg S. Hydrogels: from controlled release to pH-responsive drug delivery. Drug Discov Today. 2002;7(10):569-579.

24. Horcajada P, Serre C, Maurin G, et al. Flexible porous metal-organic frameworks for a controlled drug delivery. J Am Chem Soc. 2008; 130(21):6774-6780.

25. Slowing II, Vivero-Escoto JL, Wu CW, Lin VS. Mesoporous silica nanoparticles as controlled release drug delivery and gene transfection carriers. Adv Drug Deliv Rev. 2008;60(11):1278-1288.

26. Zhao W, Wang H, Feng X, Zhang Y, Zhang S. Control over the morphology of TiO2 hierarchically structured microspheres in solvothermal synthesis. Mater Lett. 2015;158:174-177.

27. Hughes E, Yanni T, Jamshidi P, Grover LM. Inorganic cements for biomedical application: calcium phosphate, calcium sulphate and calcium silicate. Adv Appl Ceramic. 2015;114(2):65-76.

28. van de Belt H, Neut D, Schenk W, et al. Gentamicin release from polymethylmethacrylate bone cements and Staphylococcus aureus biofilm formation. Acta Orthop Scand. 2000;71(6):625-629.

29. Neut D, Dijkstra RJ, Thompson JI, van der Mei HC, Busscher HJ. Antibacterial efficacy of a new gentamicin-coating for cementless prostheses compared to gentamicin-loaded bone cement. J Orthop Res. 2011;29(11):1654-1661.

30. Cho SB, Nakanishi K, Kokubo T, et al. Dependence of apatite formation on silica gel on its structure: effect of heat treatment. J Am Ceramic Soc. 1995;78(7):1769-1774.

31. Sukhorukova IV, Sheveyko AN, Manakhov A, et al. Synergistic and long-lasting antibacterial effect of antibiotic-loaded TiCaPCON-Ag films against pathogenic bacteria and fungi. Mater Sci Eng C Mater Biol Appl. 2018;90:289-299.

32. Pang Q, Nazar LF. Long-Life and High-Areal-Capacity Li-S Batteries Enabled by a Light-Weight Polar Host with Intrinsic Polysulfide Adsorption. ACS Nano. 2016;10(4):4111-4118.

33. Slane J, Vivanco J, Meyer J, Ploeg HL, Squire M. Modification of acrylic bone cement with mesoporous silica nanoparticles: effects on mechanical, fatigue and absorption properties. J Mech Behav Biomed Mater. 2014;29:451-461.

34. Lee BY, Kurtis KE. Influence of $\mathrm{TiO} 2$ Nanoparticles on Early C3S Hydration. J Am Ceram Soc. 2010;93(10):3399-3405.

35. Mohammadi M, Hesaraki S, Hafezi-Ardakani M. Investigation of biocompatible nanosized materials for development of strong calcium phosphate bone cement: Comparison of nano-titania, nano-silicon carbide and amorphous nano-silica. Ceram Int. 2014;40(6):8377-8387.

36. Johari N, Madaah Hosseini HR, Samadikuchaksaraei A. Optimized composition of nanocomposite scaffolds formed from silk fibroin and nano- $\mathrm{TiO}_{2}$ for bone tissue engineering. Mater Sci Eng CMater Biol Appl. 2017;79:783-792.

37. Shen SC, Ng WK, Shi Z, Chia L, Neoh KG, Tan RB. Mesoporous silica nanoparticle-functionalized poly(methyl methacrylate)-based bone cement for effective antibiotics delivery. J Mater Sci Mater Med. 2011;22(10):2283-2292.

38. Frutos G, Pastor JY, Martínez N, Virto MR, Torrado S. Influence of lactose addition to gentamicin-loaded acrylic bone cement on the kinetics of release of the antibiotic and the cement properties. Acta Biomater. 2010;6(3):804-811.

39. Pei P, Wei D, Zhu M, et al. The effect of calcium sulfate incorporation on physiochemical and biological properties of 3D-printed mesoporous calcium silicate cement scaffolds. Microporous Mesoporous Mater. 2017;241:11-20 
40. Wang S, Liu F, Zeng Z, Yang H, Jiang H. The Protective Effect of Bafilomycin A1 Against Cobalt Nanoparticle-Induced Cytotoxicity and Aseptic Inflammation in Macrophages In vitro. Biol Trace Elem Res. 2016;169(1):94-105.

41. Takahashi T, Ueda S, Takahashi K, Scow RO. pH-dependent multilamellar structures in fetal mouse bone: possible involvement of fatty acids in bone mineralization. Am J Physiol. 1994;266(3 Pt 1): C590-C600.

42. Huan Z, Chang J. Self-setting properties and in vitro bioactivity of calcium sulfate hemihydrate-tricalcium silicate composite bone cements. Acta Biomater. 2007;3(6):952-960.

43. Generosi A, Smirnov VV, Rau JV, Albertini VR, Ferro D, Barinov SM. Phase development in the hardening process of two calcium phosphate bone cements: an energy dispersive X-ray diffraction study. Mater Res Bullet. 2008;43:561-571.
44. Engstrand J, Aberg J, Engqvist H. Influence of water content on hardening and handling of a premixed calcium phosphate cement. Mater Sci Eng C Mater Biol Appl. 2013;33(1):527-531.

45. Aberg J, Engstrand J, Engqvist H. Influence of particle size on hardening and handling of a premixed calcium phosphate cement. JMater Sci Mater Med. 2013;24(4):829-835.

46. Habraken W, Habibovic P, Epple M, Bohner M. Calcium phosphates in biomedical applications: materials for the future? Mater Today. 2016; 19(2):69-87.

47. Apelt D, Theiss F, El-Warrak AO, et al. In vivo behavior of three different injectable hydraulic calcium phosphate cements. Biomaterials. 2004;25(7-8):1439-1451.

48. Erskine RJ, Walker RD, Bolin CA, Bartlett PC, White DG. Trends in antibacterial susceptibility of mastitis pathogens during a seven-year period. J Dairy Sci. 2002;85(5):1111-1118.
International Journal of Nanomedicine

\section{Publish your work in this journal}

The International Journal of Nanomedicine is an international, peerreviewed journal focusing on the application of nanotechnology in diagnostics, therapeutics, and drug delivery systems throughout the biomedical field. This journal is indexed on PubMed Central, MedLine, CAS, SciSearch $®$, Current Contents $\AA /$ Clinical Medicine,

\section{Dovepress}

Journal Citation Reports/Science Edition, EMBase, Scopus and the Elsevier Bibliographic databases. The manuscript management system is completely online and includes a very quick and fair peer-review system, which is all easy to use. Visit http://www.dovepress.com/ testimonials.php to read real quotes from published authors.

Submit your manuscript here: http://www.dovepress.com/international-journal-of-nanomedicine-journal 